\section{Maintenance of certification and gastroenterology}

\author{
Connie M Switzer MD FRCPC
}

Chair, CAG MOCERT committee

W illiam Osler said (1): "If the license to practice meant the completion of his education how sad it would be for the practitioner, how distressing to his patients!"

Gastroenterologists, like all physicians, are expected to remain current in their area of expertise, demonstrating leadership, skill and knowledge in the care of patients with gastrointestinal (GI) conditions.

The Royal College of Physicians and Surgeons of Canada (RCPSC) have mandated that all specialists must participate in the Maintenance of Certification Program (MOCERT). Participation by Fellows allows for the use of the designation FRCPC or FRCSC, as well as listing by RCPSC in the "Public Directory of Fellows" which will be made public in 2006.

All Fellows are automatically entered into the program. Fellows are required to submit their hours of participation in Continuing Professional Development (CPD) activities to the RCPSC by the end of each calendar year. Fellows are required to complete at least 400 credits in each five-year cycle with a minimum of 40 credits per year. The current five-year cycle finishes in December 2005.

Participation rates among Canadian gastroenterologists have been excellent. Just over $82 \%$ were participating at the end of 2003 and only a few were not participating by midway into 2004. The RCPSC requires and encourages all Fellows to participate in this program and will provide advice and mentoring to any Fellow who needs assistance. These individuals may contact the RCPSC directly at 1-800-461-9598 or at the RCPSC Web site < www.rcpsc.medical.org>.

The objectives of the MOCERT program are to ensure that Fellows are engaged in professional development and to provide standard documentation for Fellows to use to record CPD activities. This program allows Fellows to obtain CPD credits in six different categories (sections 1 to 6), thereby, allowing individuals to tailor their CPD activities to meet their own educational needs. Sections 1, 3, 4 and 5 allow Fellows to claim unlimited credit hours. At this time, sections 2 and 6 allow for limited hours but in the next cycle, section 6 will allow for unlimited credit hours for "scholarly pursuits". A complete description of these categories is available on the RCPSC Web site.

Participation in MOCERT is not only mandatory for Fellows to use the FRCPC designation, but it is also very

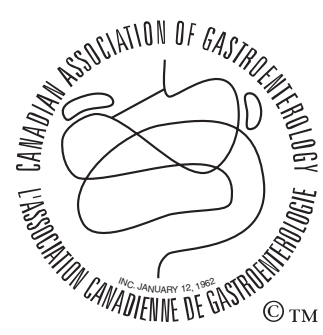

En français voir page 745 helpful in completing documents for hospital privileges and annual reports. Participation may also become mandatory for provincial re-licensure in the future. Provincial medical licensing bodies across the country are developing strategies to assess whether all physicians are maintaining their skills and competence. In the future, re-licensure may be linked, at least in part, to continued participation in the RCPSC MOCERT program.

The most common category of credit hours claimed by gastroenterologists in 2003 was section 1, accounting for $45 \%$ of all credit hours. Section 2 accounted for $21 \%$ of credit hours, section 6 for $18 \%$, section 4 for $9 \%$, section 5 for $5 \%$ and section 3 for $3 \%$. The RCPSC is encouraging Fellows to increase their use of section 4 credit hours (personal learning projects) and section 5 (practice audits). Each of these CPD categories requires documentation but allow the Fellow to develop their own projects and complete them on their own time-line. The Canadian Association of Gastroenterology (CAG) has been very active in developing programs for practice audit, such as the PAGE programs, thereby, allowing members to review his or her own pattern of practice and compare them with national data.

The CAG is an approved 'Accredited Provider' by the RCPSC. The CAG, through its MOCERT committee, assesses and approves GI educational activities for gastroenterologists across Canada. The MOCERT committee of the CAG determines if these educational programs meet the strict guidelines for Category 1 Credit approval. From 2002 to 2003, the committee approved 25 programs for $152 \mathrm{~h}$ of Category 1 Credit. These programs represent superb GI educational opportunities throughout Canada. In 2004, the MOCERT committee has continued to be very active in reviewing and accrediting educational activities aimed at advancing the science and practice of gastroenterology.

The MOCERT committee of the CAG encourages all members to remain committed to their own education and professional development and we invite all members to attend CAG-approved educational programs.

\section{REFERENCE}

1. Silverman ME, Murray TJ, Bryan CS, eds. The Quotable Osler. Philadelphia: The American College of Physicians, 1998:197.
Abbott Laboratories Ltd.
AstraZeneca Canada Inc.
Axcan Pharma Inc.
Janssen-Ortho Inc.
Pfizer Canada Inc. 


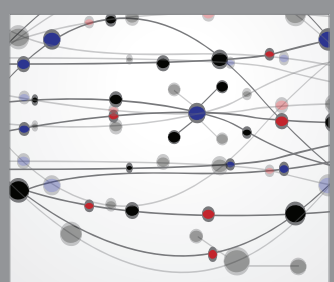

The Scientific World Journal
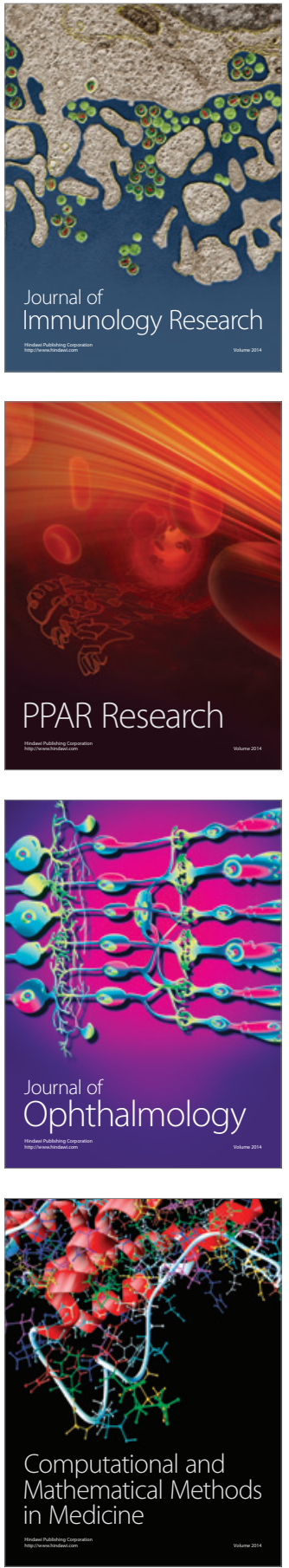

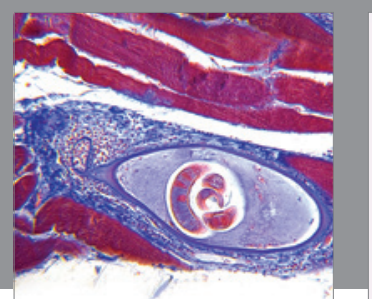

Gastroenterology Research and Practice

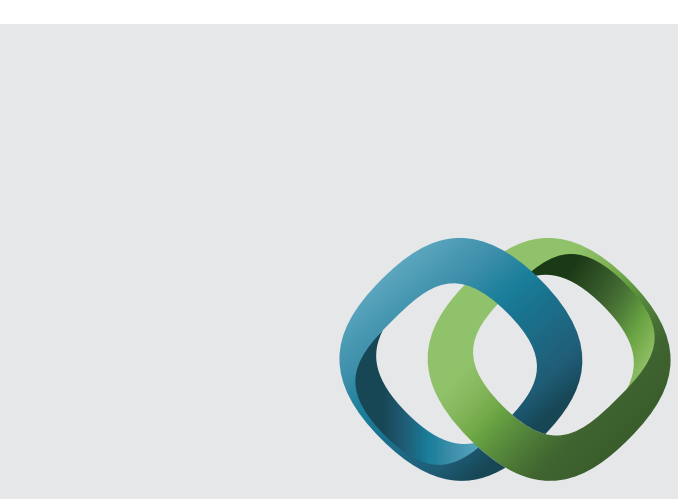

\section{Hindawi}

Submit your manuscripts at

http://www.hindawi.com
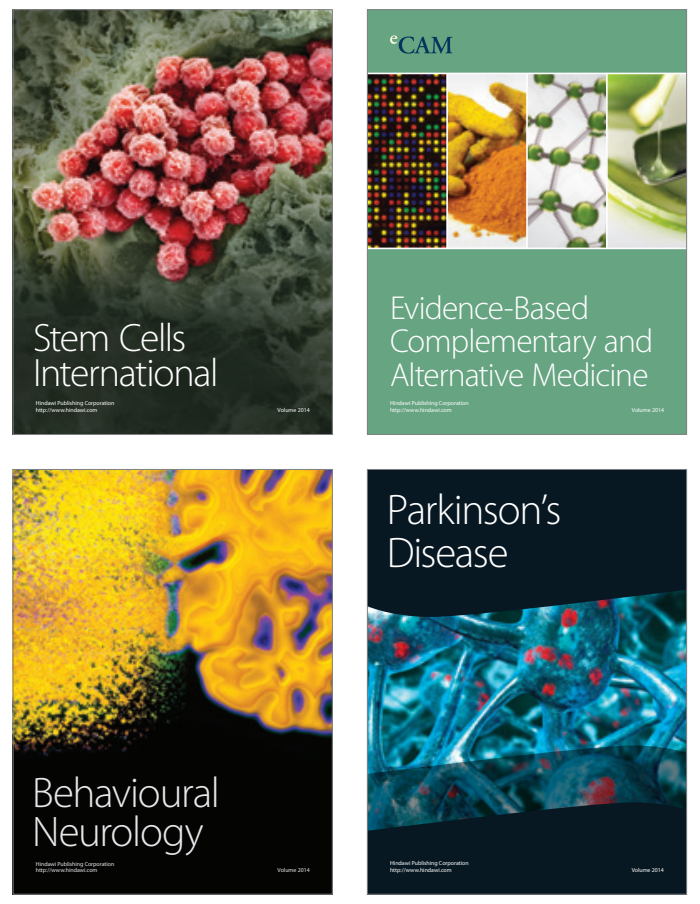
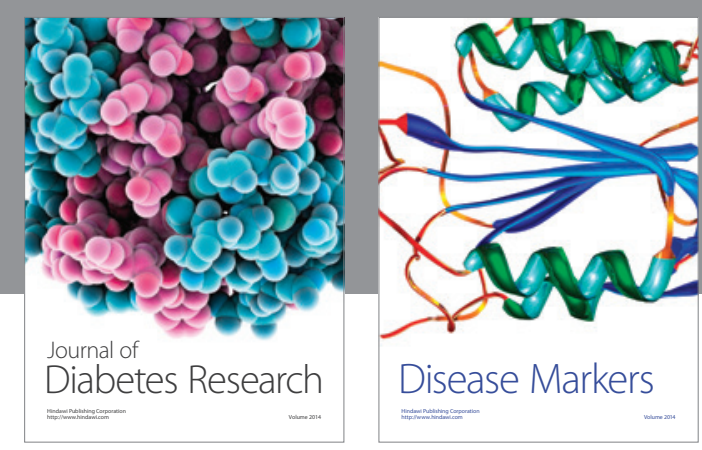

Disease Markers
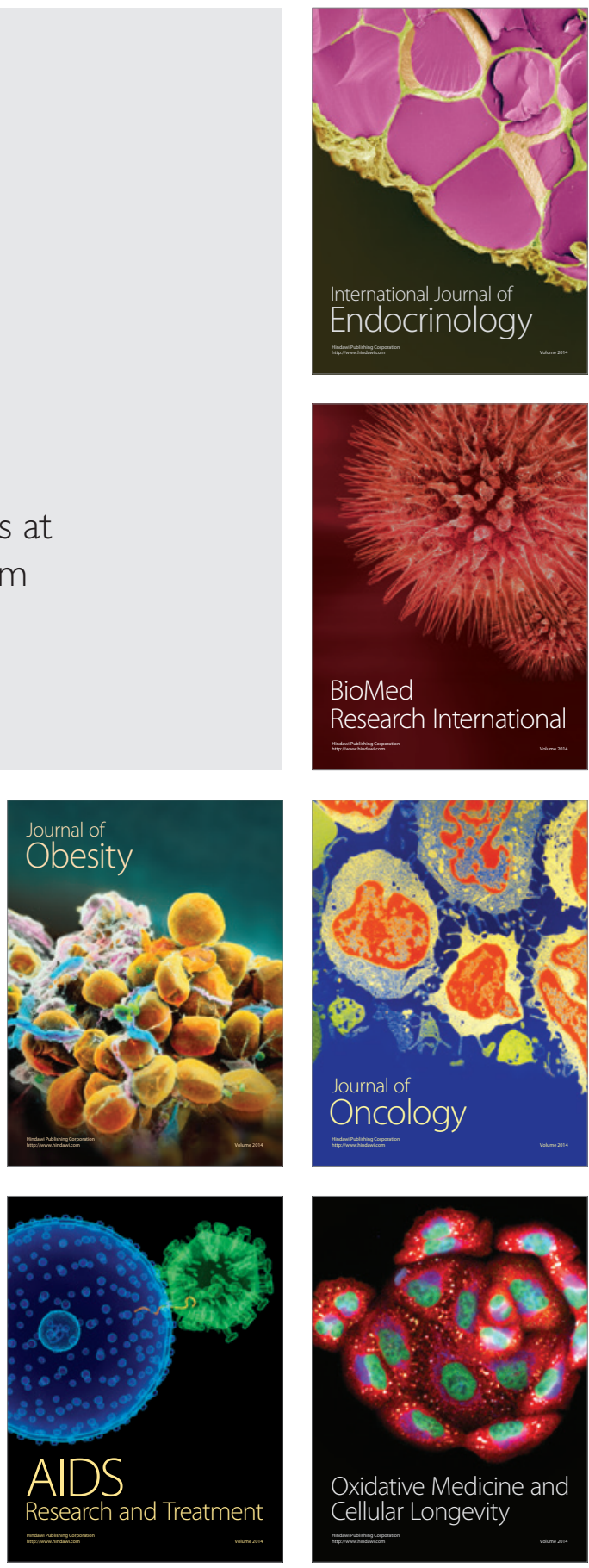